\title{
Characterization of fennel (Foeniculum vulgare L.) Genotypes on the Basis of Seed Characteristics
}

\author{
Sumit Deswal", T.P. Malik and S.K. Tehlan \\ Department of Vegetable Science, CCS Haryana Agricultural University, \\ Hisar-125004, Haryana, India \\ *Corresponding author
}

A B S T R A C T

\begin{tabular}{|l|}
\hline Ke y w or d s \\
$\begin{array}{l}\text { Characterization, } \\
\text { Genotypes, Schematic } \\
\text { diagram. }\end{array}$ \\
\hline Article Info \\
\hline $\begin{array}{l}\text { Accepted: } \\
\text { 28 September } 2017 \\
\text { Available Online: } \\
\text { 10 October } 2017\end{array}$ \\
\hline
\end{tabular}

\section{Introduction}

Fennel (Foeniculum vulgare L.) member of family Apiaceae and native to the Mediterranean region is a medicinal and an aromatic herb. It is primarily grown for its seeds. Dried fennel seeds, the aromatic, anise - flavored spices are brown or green in colour when fresh, slowly turning green to dull grey. The seeds of fennel have an active substance, which is called essential oil and most important constituent is anethole that is used in pharmaceutical, food, perfumery and favoring industry (Miraldi, 1999; Sephidkon, 2001). Fennel essential oil possesses valuable antioxidant, and has antibacterial, anticancer and antifungal activity (Lucinewton et al., 2005; El-Alwadi and Esmat, 2010). Mature fennel fruits are used as flavoring agents in food products such as pickles, bread, pastries and cheese (Zoubiri et al., 2014). Fennel fruits are used in diseases like cholera, nervous disorders, constipation, dysentery and colic pain. It also contains minerals and vitamins like calcium, potassium, sodium, iron, phosphorus, thiamine, riboflavin and vitamin C. Characterization should provide a standardized record of readily assessable plant 
characters. Germplasm characterization is carried out in precision fields by spaced planting under adequate agronomic conditions and plant protection. For each accession several morpho-agronomic traits are recorded using the descriptors. Descriptors of genotypes of crop species are required for varietal identity, determining varietal purity, establishing the distinctness of the new genotypes from existing varieties and documentation of genetic resources.

Descriptors of varieties of crop species are basis for varietal identity, determination of varietal purity, to establish the distinctiveness of new variety from existing varieties and documentation of genetic resources. A large number of genotypes are available in fennel. The systematic record of these genotypes can be obtained by genotypic characterization based on agronomic and morphological traits. Seed based descriptors are highly heritable, can be easily seen by the eyes and are expressed in all environments.

By keeping in view the above aspects, this experiment was planned and conducted at Vegetable Research Farm of CCS Haryana Agricultural University, Hisar during 2015-16 and again in 2016-17 with the objective to identify and characterize the various fennel genotypes on basis of seed based morphological descriptors and to develop identification keys for distinguishing different coriander genotypes using schematic diagram.

\section{Materials and Methods}

The present experiment was carried out during Rabi season 2015-2016 and2016-17 at Chaudhary Charan Singh Haryana Agricultural University, Hisar. The field experimental site was located at Vegetable Science farm, Hisar that is between $29.15^{\circ} \mathrm{N}$ latitude $75.69^{\circ} \mathrm{E}$ longitudes with a mean altitude of $215 \mathrm{~m}$ above msl. Sixty genotypes of fennel seeds were collected from different locations of India (Gujarat, Haryana and Rajasthan).

These diverse genotypes were sown (13 November 2016) with Augmented block design having four blocks with fifteen entries in each block and having plot size of $3.0 \mathrm{~m} \times$ $1.0 \mathrm{~m}$ with spacing of $50 \mathrm{~cm} \times 20 \mathrm{~cm}$. All recommended agronomic practices were followed timely for successful raising the crop. Ten competitive plants from each plot were randomly selected. The seed harvested from these ten plants were taken for recording of data pertaining to seed morphological characters.

\section{Seed shape}

The shape of seed was observed with the help of magnifying glass and genotypes were grouped into oblong, oval and ellipsoidal shaped.

\section{Seed colour}

The seed colour was observed visually and genotypes were grouped as light green, brown and dark brown.

\section{Seed splitting}

Seed splitting was observed visually whether seed splitting of seed was present or not.

\section{Seed ridges}

The ridges on the seeds were observed visually whether ridges on the seed were prominent or non- prominent.

\section{Number of Seed ridges}

The ridges on the seeds were visually observed by counting the number of ridges on mature dry seed. 


\section{Test weight (g)}

From each genotype seed lot, 1000 seeds were separated and weight was calculated in gram. Finally genotypes were characterized into light $(<5 \mathrm{~g})$, and heavy $(>10 \mathrm{~g})$.

\section{Schematic diagram}

A schematic diagram was prepared to classify all sixty-four genotypes based on seed characters (Figure 1).

\section{Results and Discussion}

A number of seed characters such as seed shape, seed colour, seed splitting, seed ridges, number of ridges and test weight $(\mathrm{g})$ were studied for characterization of sixty genotypes of fennel. The seed colour of the genotypes was observed visually and they were categorized into dark brown, and light brown. Thirty six genotypes were observed as light brown, and twenty four genotypes were under dark brown seed colour (Table-1).

Seed shape of the genotypes was observed visually and they were categorized into three groups i.e. ellipsoidal, oblong and oval. Seven genotypes were observed as ellipsoidal, thirty observed as oblong shape and twenty three were observed as oval seed shape (Table-2). The seed splitting habit of the genotypes was observed visually and they were categorized into two groups i.e. non-splitting and splitting. Fifty seven genotypes were observed as nonsplitting and three genotypes observed as splitting characteristics (Table-3).

On the basis of visual observation of all the sixty genotypes, three genotypes having less number of ridges and fifty seven observed having more number ( $>5)$ ridges on seeds (Table-4). On the basis of visual observation of all the sixty genotypes, twenty genotypes having non-prominent ridges on seeds and forty genotypes were observed having prominent ridges on seeds observed (Table5). Similar characterization on basis of shape, colour and splitting of seed was done by Amit (2012); Singh (2011) and Subramaniam and Ramakrishnan (1978) and found considerable variation for further improvement on the basis of seed characterization. The test weight (1000-seed weight) of all fennel genotypes ranged from $3-6.4$ g. accordingly, two categories were made viz., thirty four genotypes were found to have lightweight $(<5$ g) seed, and twenty six genotypes have heavy weight $(>5 \mathrm{~g})$ seed as presented in Table- 6 . Awas et al., (2015) reported that range for thousand seed weight was 3.25-14.14 g with mean of 9.5 (g). Bhandari and Gupta (1993) reported thousand seed weight range of 5-22.1 $\mathrm{g}$ in coriander. Mengesha and Alemaw (2010) reported 9.8-12.8 g thousand seed weight range in coriander genotypes. Similarly, Cosge et al., (2009) reported 3.57-15.72 g range in thousand seed weight in sweet fennel. The identification key has a pivotal role to identify the genotypes in filed and laboratory without any use of costly chemicals and are fairly comparable with their results.Based on seed colour sixty genotypes were characterized into three sub groups i.e. light dark brown and dark brown and sub group of seed shape were characterized into oval, oblong and epicedial. Further these subgroups were classified on the basis of seed weight into heavy and light were identified. Schematic diagram (identification key) for genotypes identification on the basis of plant morphological characters presented in fig-1. Tanuj (2014) made the schematic diagram of the important morphological traits of fennel and find higher resolution in terms of differentiating among genotypes. Yadav (2016) represents the identifications with the help of schematic diagram for the coriander seed characters and growth parameters and found useful for the identification of genotypes. 
Fig.1 Schematic diagram (identification key) based on morphological character for genotypes of fennel

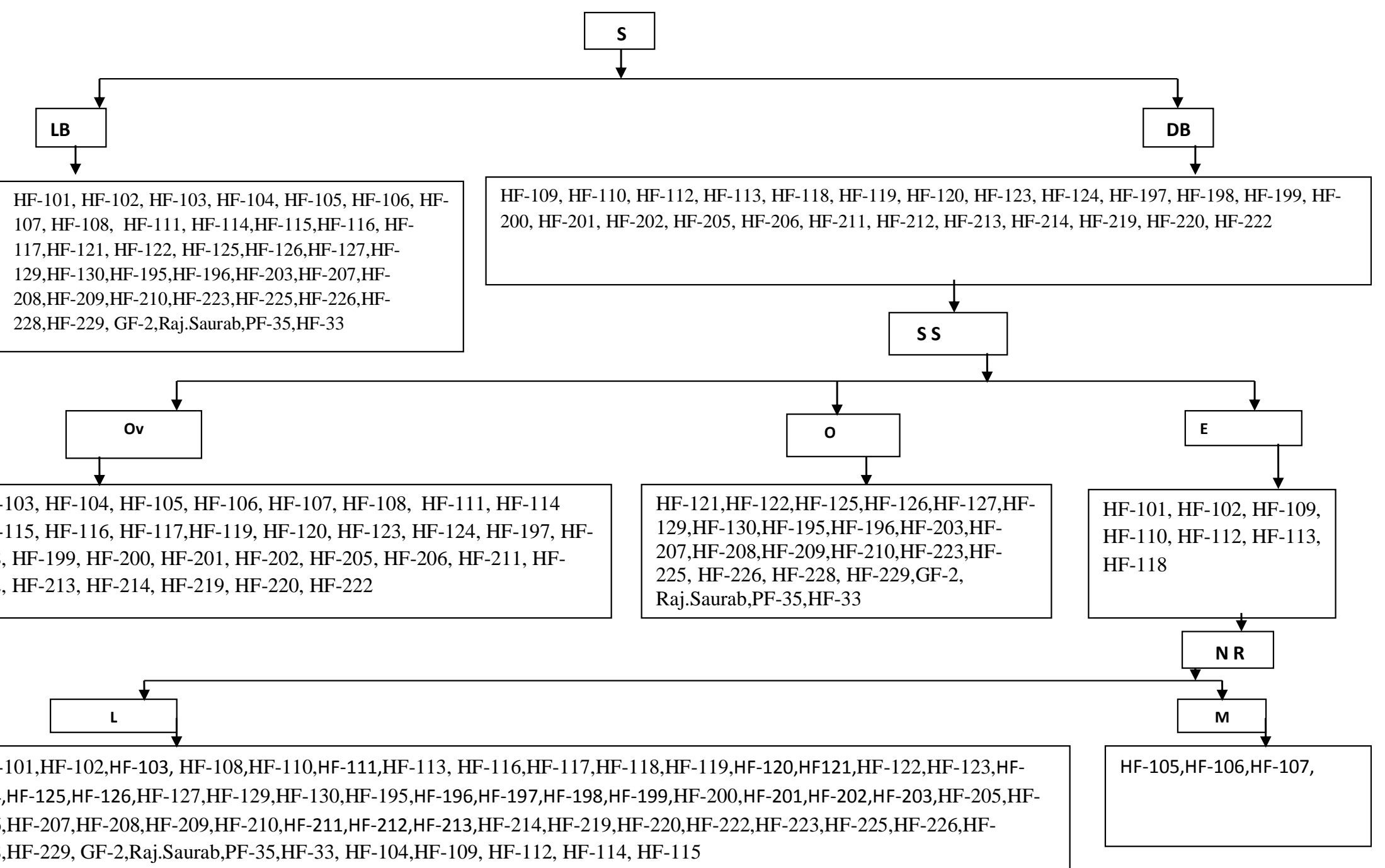

228,HF-229, GF-2,Raj.Saurab,PF-35,HF-33, HF-104,HF-109, HF-112, HF-114, HF-115

$\mathrm{S}=$ Seed colour $(\mathrm{LB}=$ light Brown, $\mathrm{DB}=$ dark brown), $\mathrm{S} \mathrm{S}=$ Seed Shape $(\mathrm{Ov}=\mathrm{oval}$, O=oblong, $\mathrm{E}=$ ellipsoidal), NR = No. of Ridges $(\mathrm{L}=$ less, $\mathrm{M}=\mathrm{More})$ 
Table.1 Categorization of fennel germplasm lines based on seed color

\begin{tabular}{|l|c|l|}
\hline \multicolumn{1}{|c|}{ Category } & $\begin{array}{c}\text { Number } \\
\text { of entry }\end{array}$ & Germplasm \\
\hline $\begin{array}{l}\text { Light } \\
\text { Brown }\end{array}$ & 36 & HF-101, HF-102, HF-103, HF-104, HF-105, HF-106, HF-107, HF-108, HF-111, HF- \\
& & $\begin{array}{l}\text { 114,HF-115,HF-116, HF-117,HF-121, HF-122, HF-125,HF-126,HF-127,HF-129,HF- } \\
\text { 130,HF-195,HF-196,HF-203,HF-207,HF-208,HF-209,HF-210,HF-223, HF-225,HF- } \\
\text { 226,HF-228,HF-229, GF-2,Raj.Saurab,PF-35,HF-33 }\end{array}$ \\
\hline Dark Brown & 24 & $\begin{array}{l}\text { HF-109, HF-110, HF-112, HF-113, HF-118, HF-119, HF-120, HF-123, HF-124, HF- } \\
\text { 197, HF-198, HF-199, HF-200, HF-201, HF-202, HF-205, HF-206, HF-211, HF-212, } \\
\text { HF-213, HF-214, HF-219, HF-220, HF-222 }\end{array}$ \\
& &
\end{tabular}

Table.2 Categorization of fennel germplasm lines based on seed shape

\begin{tabular}{|l|c|l|}
\hline \multicolumn{1}{|c|}{ Category } & $\begin{array}{c}\text { Number } \\
\text { of entry }\end{array}$ & Germplasm \\
\hline Ellipsoidal & 7 & HF-101, HF-102,HF-109, HF-110, HF-112, HF-113, HF-118 \\
\hline Oblong & 30 & $\begin{array}{l}\text { HF-103, HF-104, HF-105, HF-106, HF-107, HF-108, HF-111, HF-114 HF-115, HF- } \\
\text { 116, HF-117,HF-119, HF-120, HF-123, HF-124, HF-197, HF-198, HF-199, HF-200, } \\
\text { HF-201, HF-202, HF-205, HF-206, HF-211, HF-212, HF-213, HF-214, HF-219, HF- } \\
\text { 220, HF-222 }\end{array}$ \\
\hline Oval & 23 & $\begin{array}{l}\text { HF-121,HF-122, HF-125, HF-126, HF-127,HF-129,HF-130, } \\
\text { HF-195,HF-196,HF-203,HF-207,HF-208,HF-209,HF-210,HF-223,HF-225,HF- } \\
\text { 226,HF-228,HF-229, GF-2,Raj.Saurab,PF-35,HF-33 }\end{array}$ \\
\hline
\end{tabular}

Table.3 Categorization of fennel germplasm lines based on seed splitting habit

\begin{tabular}{|l|l|l|}
\hline Category & $\begin{array}{l}\text { Number } \\
\text { of entry }\end{array}$ & Germplasm \\
\hline $\begin{array}{l}\text { Non- } \\
\text { splitting }\end{array}$ & 57 & HF-101,HF-105,HF-106,HF-107,HF-108,HF-109,HF-110,HF-111,HF-112,HF- \\
& & 113, HF-114,HF-115,HF-116,HF-117,HF-118,HF-119,HF-120HF-121,HF- \\
& & 122, HF-123,HF-124,HF-125,HF-126,HF-27, HF-129,HF-130,HF-195,HF- \\
& & 196,HF-197, HF-198, HF-199, HF-200, HF-201, HF-202,HF-203, HF-205, HF- \\
& & 206,HF-207,HF-208,HF-209,HF-210, HF-211, HF-212, HF-213, HF-214, HF- \\
& & 219, HF-220,HF-222,HF-223,HF-225,HF-226,HF-228,HF-229, GF- \\
& & 2,Raj.Saurab,PF-35,HF-33 \\
\hline Splitting & 3 & HF-102, HF-103, HF-104 \\
\hline
\end{tabular}

Table.4 Categorization of fennel germplasm lines based on number of ridges

\begin{tabular}{|l|l|l|}
\hline Category & $\begin{array}{l}\text { Number of } \\
\text { entry }\end{array}$ & Germplasm \\
\hline Less than 5 & 03 & HF-105, HF-106, HF-107 \\
\hline More than 5 & 57 & HF-101, HF-102, HF-103, HF-104,HF-108,HF-109,HF-110,HF-111,HF- \\
& & $112, \mathrm{HF}-113, \mathrm{HF}-114, \mathrm{HF}-115, \mathrm{HF}-116, \mathrm{HF}-117, \mathrm{HF}-118, \mathrm{HF}-119, \mathrm{HF}-120 \mathrm{HF}-$ \\
& & $121, \mathrm{HF}-122, \mathrm{HF}-123, \mathrm{HF}-124, \mathrm{HF}-125, \mathrm{HF}-126, \mathrm{HF}-127, \mathrm{HF}-129, \mathrm{HF}-130, \mathrm{HF}-$ \\
& & 195,HF-196,HF-197, HF-198, HF-199, HF-200, HF-201,HF-202,HF-203, HF- \\
& 205, HF-206,HF-207,HF-208,HF-209,HF-210, HF-211, HF-212, HF-213, HF- \\
& & 214, HF-219,HF-220,HF-222,HF-223,HF-225,HF-226,HF-228,HF-229, GF- \\
& 2,Raj.Saurab,PF-35,HF-33 \\
\hline
\end{tabular}


Table.5 Categorization of fennel germplasm lines based on seed ridges (appearance)

\begin{tabular}{|c|c|c|}
\hline Category & $\begin{array}{l}\text { Number of } \\
\text { entry }\end{array}$ & Germplasm \\
\hline $\begin{array}{l}\text { Non- } \\
\text { Prominent }\end{array}$ & 20 & $\begin{array}{l}\text { HF-101,HF-102,HF-103,HF-104,HF-105,HF-106,HF-107,HF-214,HF-219,HF- } \\
\text { 220,HF-222,HF-223,HF-225,HF-226,HF-228,HF-229,GF-2,Raj.Saurab,PF-35,HF- } \\
33\end{array}$ \\
\hline Prominent & 40 & $\begin{array}{l}\text { HF-108,HF-109,HF-110,HF-111,HF-112,HF-113,HF-114,HF-115,HF-116,HF- } \\
\text { 117,HF-118,HF-119,HF-120,HF-121,HF-122,HF-123,HF-124,HF-125,HF-126,HF- } \\
\text { 127,HF-129,HF-130,HF-195,HF-196,HF-197, HF-198, HF-199, HF-200, HF- } \\
\text { 201,HF-202,HF-203, HF-205, HF-206,HF-207,HF-208,HF-209,HF-210, HF-211, } \\
\text { HF-212, HF-213 }\end{array}$ \\
\hline
\end{tabular}

Table.6 Categorization of fennel germplasm lines based on (Test weight) 1000 seed weight (g)

\begin{tabular}{|c|c|c|}
\hline Category & $\begin{array}{l}\text { Number } \\
\text { of entry }\end{array}$ & Germplasm \\
\hline $\begin{array}{l}\text { Less than } \\
5 \mathrm{~g}\end{array}$ & 34 & $\begin{array}{l}\text { HF-120,HF-121,HF-123,HF-124,HF-125,HF-126,HF-127,HF-129,HF-130,HF-195,HF- } \\
\text { 196,HF-197,HF-198,HF-199,HF-200,HF-202,HF-203,HF-209,HF-210,HF-211,HF- } \\
\text { 212,HF-213,HF-219,HF-220,HF-223,HF-225,HF-226,HF,228,HF-229,GF-2, Raj.Saurb, } \\
\text { PF-35, HF-33 }\end{array}$ \\
\hline $\begin{array}{l}\text { More than } \\
5 \mathrm{~g}\end{array}$ & 26 & $\begin{array}{l}\text { HF-101,HF-102,HF-103,HF-104,HF-105,HF-106,HF-107,HF-108,HF-109,HF-110,HF- } \\
\text { 111,HF-112,HF-113,HF-114,HF-115,HF-116,HF-117,HF-118,HF-119,HF-122,HF- } \\
\text { 201,HF205,HF-206,HF-207,HF-208,HF-214 }\end{array}$ \\
\hline
\end{tabular}

Sengupta (2011) find the identification keys helpful for the grouping the genotypes in the basis important morphological traits in coriander.

Singh and Verma (2015) reported variation in morphological characters in coriander and made classification of the genotypes with identification keys.

The present study indicated that all seed based characters are genetically controlled and showing discrete variations in genotypes. Therefore, these traits were very helpful in characterization or grouping of genotypes.

The information generated from this study can be used further for the genetic improvement of fennel crop through various breeding approaches and the study could be further extended to differentiate the available fennel germplasm to claim for registration without any legal problems related to IPR issues of plant variety protection.

\section{References}

Amit 2012. Characterization of coriander genotypes MSc. Thesis. Department of Vegetable Science. CCS Haryana Agricultural University. Hisar.

Awas, G, Mekbib, F. and Ayana A. 2015. Variability, heritability and genetic advance for some yield and yield related traits and oil content in Ethiopian coriander. International Journal of Plant Breeding and Genetics. 9(3): 116125.

Bhandari, M.M. and Gupta A. 1993. Association analysis in coriander. Indian Journal of Genetics. 53: 66-70.

Cosge B, Ipek A. and Gurbuz B. 2009. Some phenotypic selection criteria to improve seed yield and essential oil percentage of sweet fennel (Foeniculum vulgare Mill. var. dulce). Tarim Bilimleri Dergis. 15: 127-133

El-Alwadi M.E and Esmat, A.H. 2010. Physiological responses of fennel 
(Foeniculum vulgare Mill) plants to some growth substances. Journal of American Science, 6, 985-991.

Lucinewton S, Raul, N, Carvalho J, Mirian, B, Lin C, and Angela A. 2005. Supercritical fluid extraction from fennel (Foeniculum vulgare Mill) global yield composition and kinetic data.J. of Supercritical Fluilds, 35,212-219.

Mengesha B. and Alemaw G. 2010. Variability in Ethiopian coriander accessions for agronomic and quality traits. African Crop Science Journal. 18(2): 43-49.

Miranldi E.1999. Comparision of the essential oil from ten Foeniculum vulgare Miller samples of fruits of different origin. Flavour and Fragrance J., 14:379-382

Sengupta Debabrata. 2011. Characterization of fenugreek genotypes/cultivars by field and laboratory techniques. M.Sc. Thesis, CCS Haryana Agricultural University, Hisar, Haryana, India.

Sephidkon F. 2001. Evalution of quantitative and qualitative of fennel (Foeniculum vulgare) essential oil in different stages. Iran. J. Med. Aroma. Plants, 4: 85-101
Singh R.K. 2011. Morphological, chemical and molecular characterisation and seed vigour studies in coriander (Coriandrum sativum L.). Ph.D. Thesis, submitted to CCS Haryana Agricultural University, Hisar, India

Subramaniam S. and Ramakrishnan, V. 1978. Identification of rice varieties by laboratory techniques. Seed Research. 6(1): 71-86.

Tanuj 2014. Characterization of fennel genotypes (Foeniculum vulgare Mill) M.Sc. Thesis, CCS Haryana Agricultural University, Hisar, Haryana, India

Yadav S. 2016. Genotypic Characterization and seed vigour assessment of coriander (Coriandrum sativum L.)Ph.D. Thesis. Department of Vegetable Science. CCS Haryana Agricultural University. Hisar

Zoubiri. S., Baaliouamer. A, Seba. N., Chamouni N. 2014. Chemical composition and larvicidal activity of Algerian Foeniculum vulgare Seed essential oil. Arab J. Chem. 7(4):480485.

\section{How to cite this article:}

Sumit Deswal, T.P. Malik and Tehlan, S.K. 2017. Characterization of fennel (Foeniculum vulgare L.) Genotypes on the Basis of Seed Characteristics. Int.J.Curr.Microbiol.App.Sci. 6(10): 3671-3677. doi: https://doi.org/10.20546/ijcmas.2017.610.431 